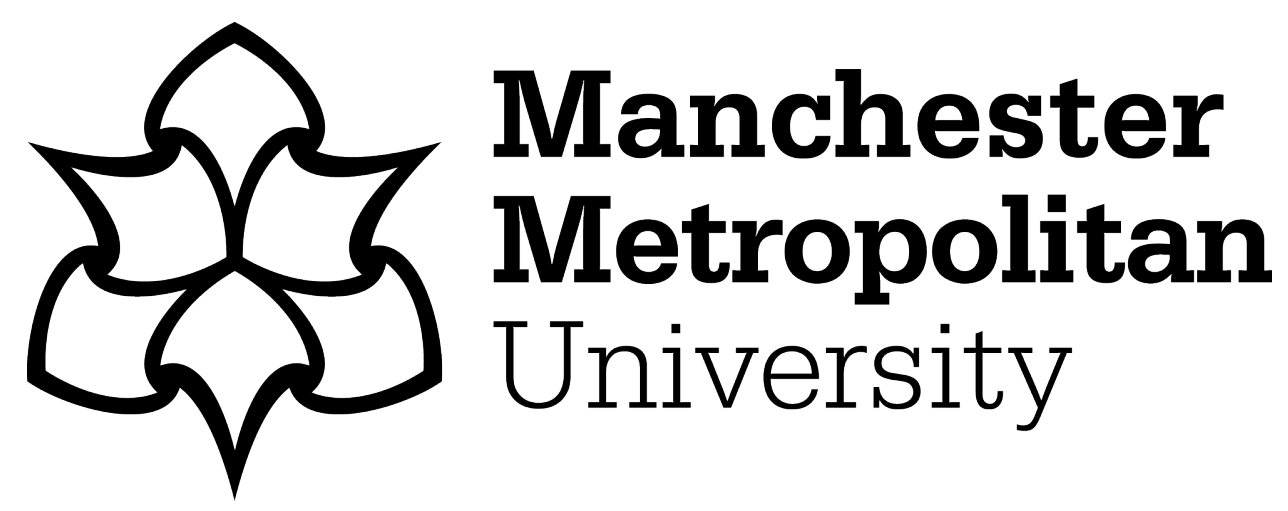

Gibbons, Andrea, Madoc-Jones, Iolo, Ahmed, Anya ORCID logoORCID: https://orcid.org/0000-0002-6164-0656, Jones, Katy ORCID logoORCID: https://orcid.org/0000-0002-8090-4557, Rogers, Michaela and Wilding, Mark (2019) Rural Homelessness: Prevention Practices in Wales. Social Policy and Society, 19 (1). pp. 133-144. ISSN 1474-7464

Downloaded from: https://e-space.mmu.ac.uk/623623/

Publisher: Cambridge University Press (CUP)

DOI: https://doi.org/10.1017/S1474746419000368

Please cite the published version 


\title{
Rural Homelessness: Prevention Practices in Wales
}

\section{Andrea Gibbons*, Iolo Madoc-Jones**, Anya Ahmed***, Katy Jones ${ }^{\dagger}$, Michaela Rogers ${ }^{\ddagger}$ and Mark Wilding ${ }^{\S}$}

\author{
*University of Salford \\ E-mail: A.R.Gibbons1@salford.ac.uk \\ **Wrexham Glyndŵr University \\ E-mail: i.m.jones@glyndwr.ac.uk \\ ***University of Salford \\ E-mail: A.Ahmed@salford.ac.uk \\ ${ }^{\dagger}$ Manchester Metropolitan University \\ E-mail: katy.jones@mmu.ac.uk \\ ${ }^{\ddagger}$ University of Sheffield \\ E-mail: m.rogers@sheffield.ac.uk \\ §University of Salford \\ E-mail: M.A.Wilding@salford.ac.uk
}

\begin{abstract}
Homelessness is largely understood as an urban issue and so rural homelessness is to a large extent invisible in both academic literature and in policy and practice discussions, just as it is often invisible in discourses of everyday rural life. This article draws on extensive interviews with homeless service users and providers in three rural authorities in Wales to give a clearer sense of the nature and challenges of rural homelessness. The article documents and explores the very different strategies employed by those facing homelessness in the rural context, as well as those of rural local authorities providing them preventative and person-centred support. Analysis of the struggle of many rural households to remain in place, often at the cost of homelessness and lowered ability to access services, will have resonance in a range of contexts and have implications for policy makers and practitioners in rural contexts beyond Wales.
\end{abstract}

Keywords: Homelessness, housing policy, prevention, local connection, rural.

\section{Introduction}

Defining 'rurality' is a complex endeavour. Industrialisation, population growth, and the advent of mass communication technologies (and more latterly the internet) arguably make defining what constitutes a rural setting a more complex endeavour than may once have been the case (Stephenson, 2001). Like many abstract concepts, the term defies a watertight and culturally neutral definition but in England and Wales the Office for National Statistics quantifies rural areas as those with populations of under 10,000 (ONS, 2018). Conversely the Welsh Government defines rural as an area that has a population density below the Wales average of 140 persons per square kilometre (Welsh Government, 2008). On either of these bases Wales is almost entirely 'geographically' a rural country. Although the North and South coasts of the country are densely populated 
and therefore urban, around a third of the population of Wales, under either definition, would be found in the large rural centre of the country.

In 2009, as preparation for drawing up the new homelessness legislation, the Welsh Assembly initiated processes to review the legal duty on local authorities to house homeless people (Fitzpatrick et al., 2012; Mackie, 2014). The ultimate aim was to produce a new strategy around homelessness able to provide 'all-encompassing service provision' which would be cost neutral in terms of its impact (Mackie, 2014: 2 quoting Welsh Government, 2009: 26). Yet, in the reports and summary papers that were subsequently produced, the rural nature of Wales was specifically mentioned only a handful of times (Fitzpatrick et al., 2012). This follows a general phenomenon whereby in western societies homelessness is overwhelmingly spoken of as an urban issue (First et al., 1994; Waegemakers Schiff et al., 2015). Yet where the issues have been explored in rural settings, different experiences of homelessness and associated patterns of survival and solutions may be reported (Milbourne and Cloke, 2006). In this context, this article examines rural homelessness in Wales and specifically whether the new focus on homelessness prevention in the Housing (Wales) Act 2014 (hereafter 'The Act') has impacted on this experience.

\section{Rural homelessness in Wales}

Some relevant literature has explored the experiences of those who face homelessness in rural contexts. Papers have explored, for example, the experience of indigenous people in Canada and those who may experience homelessness associated with trailer park use in the USA (Milbourne and Cloke, 2006). A common thread that connects the experience of rural homelessness across these national boundaries is its relative invisibility as a social policy concern (Cloke et al., 2001b; Blythe, 2006; Milbourne et al., 2006). For the most part accounts of homelessness focus on a construction that primarily associates the phenomenon with particular types of people and spaces. Specifically the rough sleeper in shop doorways in urban settings (Cloke et al., 2001a). As relevant as that manifestation of rooflessness is, a sole focus on this is problematic as it can obscure the broader ways homelessness might be experienced and concentrate discussion, and ultimately resources, only on homelessness in one setting.

Additional discursive constructions may further direct attention away from rural homelessness. Specifically those that contrast the progressiveness of the urban with the backwardness of the rural and which may construct the experience of homelessness as less problematic for some groups (Sandberg, 2013). At the broader level, conceptions of the 'rural' are also strongly linked to an idyllic and often nationalised vision of landscape and a community rooted in time and place which leaves little room for considerations of the existence of those who literally have no place to call home (Cloke et al., 2001b; Robinson, 2004). More locally, individualism and self-sufficiency are often noted as core rural cultural values (Carpenter-Song et al., 2016) and this may create a disincentive to recognise the issue of homelessness within rural communities themselves (Milbourne and Cloke, 2006; Waegemakers Schiff et al., 2015).

Lack of attention to rural homelessness is highly problematic given the specific challenges in finding accommodation raised for those at risk of homelessness in such settings. In many rural contexts avoiding homelessness may be challenging due to poverty and fewer employment opportunities. In Wales, for example, rates of poverty and 
unemployment are higher than the UK as a whole (Public Policy Institute for Wales, 2016). Lack of affordable housing may be associated with fewer new builds, but also in-migration of wealthier households retiring to the country and the use of homes as holiday lets (Cloke et al., 2001a; Robinson, 2004; Milbourne and Cloke, 2006; Kitchen and Milbourne, 2006; Snelling, 2017). At the same time specific services for people facing housing difficulties or homelessness may be poorly developed and/or difficult to access. Those unable to drive or afford a car and dependant on public transport in rural settings may frequently find they face poverty of access to all sorts of key services (Gray et al., 2006). At the same time, access to service online via the internet may be unsupported or poorly developed (Williams and Doyle, 2016).

Some accounts of rural homelessness address themselves to issues of identity and connection to the land (Cloke et al., 2001b; Milbourne and Cloke, 2006; Milbourne, 2012). This has been associated in some contexts with concerns about the treatment of indigenous communities - for example in Australia (Argent and Rolly, 2006), Canada (Waegemakers Schiff et al., 2015), and the USA (Lawrence, 1995; Shapiro, 2014). In Wales the impact homelessness and in-migration may have on the concentration of people in rural areas able to speak the Welsh language has been of concern (Gallent et al., 2018). In Wales language and identity are linked so that the ability to speak Welsh is a defining national characteristic (Madoc-Jones et al., 2012). The ability to speak a language, and thereby express an identity, however, is dependent on a sufficient number of people with similar linguistic abilities living in proximity to one another. Accordingly efforts to reduce the outmigration of Welsh speaking people who would prefer, but find themselves unable, to afford to stay in their local area may arise (Institute for Welsh Affairs, 2006; Kitchen and Milbourne, 2006). Here, the effort to address homelessness may be imbued with special significance and associated with imperatives to preserve national identity. While acknowledging the often damaging idealisation of rural communities described by Cloke et al. (2001b) which can serve to further stigmatise and make invisible homeless households, existing literature identifies households in rural settings willing to endure high rents, poor housing conditions, caravans and doubling up with other households as part of efforts to remain in place (Milbourne and Cloke, 2006). Positive understandings of connection to place in relation to social and familial networks, employment and identity can underpin policies sympathetic to supporting the ability of people to remain in their communities of residence.

Entitlement to housing has always been conditional in England and Wales and for most of the last forty years, statutory assistance to people facing homelessness has been reserved for those deemed to be in priority need, unintentionally homeless and with local connection (Inkson, 2009; Mackie et al., 2012; Mackie, 2014). Local connection is described as having normal residence, employment, family associations or special circumstances connecting a household to an area (Welsh Government, 2016: 3.41). Under the Housing (Wales) Act 2014, local connection becomes irrelevant in relation to duties to help to prevent homelessness or secure accommodation. This removes what was a boundary separating those deemed to belong to a place, and those deemed not to belong (Cloke et al., 2001b). Local connection rules have been criticised for limiting mobility and choice, for excluding people from services who might have lived and worked in an area for a generation or more (Rogers, 1985; Cloke et al., 2001a), and accused of providing succour to anti-immigrant and xenophobic sentiment. Nonetheless, rural authorities on the whole tend to believe it should be strengthened and the time required 
to establish residency increased (Inkson, 2009; Mackie, 2014). In Wales in particular, concerns about the effects of in-migration on language use and local identity can fuel concerns about more open housing policies.

However, a broader and more open conception of the idea of 'local connection' could be promoted and offer a mechanism for transcending such debates. This would be one that understands 'local connection' as a goal to work toward rather than an existing essentialised characteristic. Such an expansive definition, one that is relational rather than static, would work on two levels, the first structural and indeed infrastructural - facilitating sustainable connection to place through access to adequate housing, income, services and transport. The second would be at the level of practice by both local authorities and third sector organisations based on the understanding that while homelessness is structural, the principal 'protective factor' against descending into homelessness is embeddedness and the existence of social support networks (Bramley and Fitzpatrick, 2018). This transforms belonging and identity, from something an individual is born into or of an essentialised identity, into something that is constantly being developed and built in relation to place

Within the framework of primary, secondary and tertiary prevention (BuschGeertsema and Fitzpatrick, 2008; Culhane et al., 2011; Fitzpatrick et al., 2012), the Housing (Wales) Act 2014 primarily extended the range of secondary and tertiary prevention provided by local authorities supporting households threatened with, or recently experiencing, homelessness. This is where local connection comes into play in the implementation of homelessness policies more specifically, but it is also central to broader government policies addressing structural issues around housing. Rural homelessness, however, may be affected by additional strategies to address the vitality of rural communities and implemented by the Welsh Government. For example, a pan Wales Rural Housing Enabler Network was established between 2008-09, and a specific rural housing fund started to support the building of affordable homes in rural settings (Welsh Government, 2018a). Before being abolished completely in early 2019, restrictions were also placed specifically on sales of housing under 'Right to Buy' in Areas of Outstanding Natural Beauty, requiring residence in the area for at least three years prior to sale (Rural Housing Solutions et al., 2014). Other policies have promoted the returning of empty homes back into use and making smaller sites available for building affordable housing (Rural Housing Solutions et al., 2014).

In Wales, one quarter of the total number of households approaching local authorities for assistance as a result of being threatened with homelessness (section 66) were in rural local authorities in 2017-2018. In the same time period, twenty-nine percent of the total number of households accepted as statutorily homeless and owed a duty to secure accommodation (Section 73) were in rural authorities (Welsh Government, 2018b). Accordingly this article examines how this group experienced their homelessness and how the local authority (LA) they approached sought to engage them in light of newly imposed prevention duties.

\section{Methodology}

This longitudinal research was conducted as part of the Post-implementation evaluation of Part 2 of the Housing Act (Wales) 2014, undertaken for the Welsh government. The evaluation results have been published in the form of an interim (Ahmed et al., 2017) and 
a final report (Ahmed et al., 2018). Six local authorities which remained anonymous in the report were chosen as sites for case studies, three of them officially classified as rural under the Welsh Government's definition as having a population density below the Wales average of 140 persons per square kilometre (Welsh Government, 2008). While the initial study design had envisaged interviewing people as they approached the LA for the first time, this was not found possible in rural areas where the volume of people presenting was lower. Researchers therefore spent additional time in these areas, working with local authorities to interview people presenting or already engaged with the LA who were at risk of, or already made homeless. A total of seventy-one initial interviews were undertaken, and thirty-three people were successfully located and agreed to be interviewed a second time after six months. These interviews were conducted in LA offices, hostels, shelters, homes and by phone. An additional thirty-five interviews and focus groups with staff from local authorities, third sector organisations and registered housing providers were undertaken. All were transcribed and thematically coded using Nvivo.

In the following section we present a thematic account of how homelessness was understood and addressed in rural settings. Respondents are identified by the notation rule: SU for service user; LA for Local Authority housing options staff; TS for third sector housing providers. While the narratives developed and chosen for inclusion in this article did not differ from those in the wider sample, they are chosen because they best articulate and more clearly present the issues which form the focus of the article.

\section{Lack of affordable housing}

The majority of local authorities (17) reported that since the Act was implemented the removal of the requirement of local connection for two of the three levels of support (the duty to 'prevention' and 'help to secure' accommodation, whereas 'final' duty to secure accommodation continues to require households be found to have priority need and local connection) had increased demands on their services. A lack of adequate and affordable housing, especially in the rented sector, however, was identified as restricting the ability of local authorities to meet need, prevent homelessness and successfully support those already homeless into permanent housing.

The adequate supply of housing was associated in some accounts with limited building activity. In talking about their building plans, social housing providers spoke of difficulties in developing housing in a rural context - lack of land and particularly large plots of land that would allow for building economies of scale, and resistance to development, often spearheaded by more wealthy landowners. A number of factors were understood to belie poor rental options in rural areas but a significant concern, as depicted in the following extract, was a perceived rise in the number of properties set aside for holiday accommodation or bought as second homes:

where we just came from a quarter of the houses now are rented out as holiday lets you see because they can get $£ 800$ to $£ 900$ a week you see, and in all the winter they're just empty and people that live in the area and work in the area can't get any housing, and private housing is definitely going down round here (SU A1)

Where such processes were ongoing, rental costs for properties available for rent were perceived to be high and on the increase (Milbourne and Cloke, 2006; 
Fitzpatrick et al., 2017; Snelling, 2017). A number of respondents described rents above the Local Housing Allowance ${ }^{1}$ and therefore expensive or out of reach for those dependant on benefits. Some households in rented properties were described as struggling to pay rent as a result of welfare reform policies and so, as one authority staff member put it, a common experience was of 'poverty in paradise':

You know you look at this fantastic part of the country to live in, but if you haven't got money in your pocket and you've got to heat the house and you've got to put food on the table and a significant amount of the cost is going on rent, it starts becoming really, it comes out high. So, it does become quite pressured then in terms of family cohesion and just living' (LA, A5).

While some of these issues that were highlighted applied in urban settings, the greater limits to both total housing stock, whether private or social, and the geographical thinness of services were understood to create particular problems in rural settings. The most frequent action to prevent homelessness was households being placed in accommodation owned by the authority itself. As welcome as this was, the choices available were thereby limited and so very few people that were interviewed described being able to remain in their preferred place. For some of those in work or with more complex needs, this could be particularly problematic:

II said to them with this property, where it is, I have a lot of hospital appointments, and some of them I have no choice about where they are because of the departments that you need to see. ... I said to them, 'There are no buses down to this property.' She said, 'You have mobility.' She said, 'Just book a taxi.' What I was trying to explain to her is the taxis from that property to town are £5. If I've got to get a taxi in the morning it's costing me $£ 5$ to get in. If I don't get back, because it's like one of the ones I had to go to in the hospital I knew then I couldn't get a bus back from, because it was an all-day appointment. (SU, A4)

\section{Significance of place}

'Place' was afforded particular significance in accounts of addressing homelessness in rural settings. Notwithstanding pressures to relocate (discussed later) service users were described as deeply embedded in their communities and reluctant to move. This could lead to homelessness being under-reported, and corroborates the findings of Robinson and Coward (2003) who noted a higher proportion of hidden homelessness in rural areas as also illustrated in the following interview:

... we have a lot of families still living at home, who don't even apply to come on the register. The families look after families. Nothing wrong with that .... the problem with that is that people don't register, so it's a perceived belief that there's no need? ... It's a rural area, it's quite different sort of thinking. They could be living in caravans, living on the yards, they manage, because that's what they want, to stay local. They want to stay in their own communities. (LA, A5)

Perceived attachments to place were not uncommon, but could be expressed in particular ways by those in rural settings. According to Melucci (1994), Mann (2006) and Day and Jones (2006), in response to globalisation, the significance of the nation-state has waned and local, often ethnic identities have become re-activated. Chambers and Thompson (2005) have argued that, as traditional bases of social and cultural identity 
have declined, a plurality of identities has emerged in Wales based on differing ideas of Wales and Welshness. Be that as it may, Pritchard and Morgan (2003) have argued that in Wales a popular cultural script revolves around the concept of the 'fro Gymraeg' - a rural place inhabited by the Welsh 'gwerin' ('Rural Welsh') who use the Welsh language. It is suggested that accounts of place in rural settings reflected this concept to emphasise a sense of belonging and entitlement to place. Accordingly one respondent said;

Welsh, my main language. So nice to be able to speak it again, you know. English are very cold people.... After period of living with a daughter in [the] English borders, I'm back in the mountains where I belong. (SU, A1)

Under the Housing (Wales) Act 2014, local connection should have become irrelevant as a consideration in relation to duties to help to prevent alleviate homelessness or secure accommodation. Significant differences were reported, however, in terms of when and how case study areas used local connection tests. There was evidence that local connection could still be used to manage and gatekeep resources:

'People take the local connection a bit too seriously: they're like, 'We don't want people from outside coming in'. Yes, 'send them back to where they came from!' (LA, A1)'

Such an approach was to some extent still facilitated by a code of guidance that had been issued to accompany implementation of the Act which, whilst stating local authorities could not refuse to accept an initial duty to help to prevent (s66) or help to secure (c73) accommodation for a homeless household, said they could prioritise people with a local connection when undertaking steps such as issuing bonds, providing rent in advance, and the use of prevention funds.

\section{Facilitating local connection}

Through the provision of outreach services local authorities and third sector organisations had sought to act as a connecting force between local villages and local government. Here the willingness of staff to come to where people were was described as particularly helpful in both the prevention of homelessness and in supporting households to move from being homeless to being housed. One hostel worker described the weekly visit from Shelter and the willingness of statutory and third sector organisations to drive down to see people in the small village where the hostel was placed as crucial to the service user experience.

However, several respondents noted that this sort of practice had become rarer as a result of austerity-driven service cuts. One of the key challenges in rural areas lay simply in the distances that people had to travel to access support - or that LA or third sector staff had to travel to provide support. A staff member could lose half a day in coming to see just one person from where they were based. Accordingly services were described as being ever-more concentrated in the centres, creating pressure for those facing homelessness in rural areas to migrate to urban centres:

North Wales is what I would define as deeply rural. You don't have static services, so if you live in a little village in the mountains, it can take you three buses to get to a city centre. Benefits don't pay your buses, so most people within this area tend to, especially around homelessness, will congregate in the area where there are services'. (TS, A1) 
Concentration of services was problematic for staff in more strategic positions who prioritised community in thinking about how best to support individuals facing homelessness in rural communities:

As I say the emphasis has been on, if we can, getting people to stay put where they are if that's feasible. Now certainly in terms of families and family groups that could be very important in terms of retaining links with their extended families, communities, also ensuring children have continuity in terms of schools. (LA, A1)

In Wales, some children attend Welsh language schools and thereby moving area could necessitate a change in the language of education with concomitant implications in terms of personal identity for these children. However, new requirements associated with the Welfare to Work Act were understood to bear down harshly on some individuals in rural settings and create additional pressures for some to relocate to urban centres. Punitive sanctions could arise for missed appointments with benefit staff, creating a perceived need for people to move. As a housing provider said:

There are sometimes problems in the individuals then getting into the benefits agency office, because they need transport to get there. So ... people that tend to gravitate towards the larger towns ... if you've got certain communities within the county, they may have two busses a day, so if you're on benefits... it can be a bit far away for them. (RP, A1)

\section{Addressing the rural context}

One Authority had responded to budget cuts by reorganising their services and investing their limited funds into a phone system and a single central hub that concentrated both council and third sector services into a single place, moving all housing support to being by phone only. While some staff at the strategic level viewed the switch to phone support as an ideal solution to reduce costs and manage staff time, frontline staff were less positive about this development because it was understood to negatively affect how they related to those seeking help and compromised their ability to provide person centred support.

Staff understood that a great deal of human information gathering and processing is predicated upon physical appearances and the presence or absence of non-verbal cues or body language. Moreover even the best technology currently available could not fully replicate the conditions of physical proximity. Baker et al. (2019) in particular identify similar findings around the importance of face to face communication for 'hard to reach' populations, such as those in rural areas. As one staff member said:

you lose so much by not seeing the person in front of you. You know what they may be saying, but what they may be feeling, it's very different' (LA, A5).

This was compounded by the significant logistical issues faced by those experiencing crisis, and particularly those rough sleeping, in having access to a working phone to make such a call.

Homeless presentations now have to be done over the phone, and I sort of have to say that if you're street homeless what's the likelihood of having a phone?... [or] having enough credit.' (TS, A4) 
Furthermore, it was mooted that if someone was experiencing distress or domestic abuse, it is not possible to discern this during a telephone call. Another respondent indicated that over the phone practice could become far more punitive than face to face:

It's quite easy to tell somebody on the phone: 'No,' and put the phone down on them. You try to do that to somebody's face... I fear sometimes that that's what's been said of us, is because we're afraid to make a decision and to actually face somebody and give them that news or to try and say: 'Right, actually, let's work through your vulnerabilities, let's look at what support we can provide.' ( $L A, A 4)$

Service users also raised these issues, one of whom commented:

'It would be nice to have somebody you can speak to face-to-face, not over the other end of the phone... When you're face-to-face, I think you don't get as frustrated as you do when you're on the phone because if you're trying to put your point across on the phone and basically they're doing other things as well while they're talking to you, it does frustrate you but when you're face-to-face then, they've got to concentrate on you.... Sometimes you don't know what they're doing, they could be reading up about something else when they're trying to talk to you on the phone'.

Better service evaluations were forthcoming in the authority that prioritised funding staff to get in their cars and drive the distances necessary to visit people in their hostels or in their homes. This was understood to facilitate work to understand the underlying causes of crisis and better connect people to relevant services. The greatest success in supporting people into secure and long term tenancies was found in these settings. In this particular council area, twenty-five of twenty-five of those interviewed felt supported by the council (as compared to six in another rural authority relying on telephones) and thirteen had moved into secure housing (ten into social housing, three into the PRS with a low degree of ongoing support) after six months (Ahmed et al., 2017, 2018). Time in particular, and the capacity to develop personal relationships with service users was highlighted by frontline staff in several authorities as central to helping people get the various services they needed to deal with the issues that were often underlying their homelessness. This also meant getting into the car and visiting people, as one frontline staff member said:

'You need to visit people who can't get out, don't you? You need to go to hospitals, you need to... And [if you don't] you know, you're not doing properly then, are you?' (A1).

\section{Conclusions}

This article builds on a small yet significant body of work that looks at the issue of rural homelessness and the multiple barriers to providing services to a scattered population whose needs are often hidden, and where social housing stock is low and private rented housing increasingly taken up by holiday lets and second homes (Milbourne and Cloke, 2006; Milbourne et al., 2006; Commission on Rural Housing in Wales, 2008). These issues have only been exacerbated by austerity and welfare reform - increasing poverty, precarity, arrears and evictions on the one hand, and local authorities facing shrinking budgets and third sector agencies competing for ever smaller pots of funding on the other. 
Two key best practices for the prevention of homelessness in rural areas emerge from the research and are based on an expansive and relational definition of 'local connection' between people and place. The first is supportive of the person-centred approach central to the Housing (Wales) Act and to the success that it has achieved to date (Ahmed et al., 2018). Such a person-centred approach is based on relationships of mutual trust and requires the building of collaborative networks - neither of which are especially easy to establish in rural settings during times of austerity. In rural areas a person-centred approach requires at minimum the funding of staff travel and time, transferring the challenge of overcoming key rural challenges of isolation, distance and invisibility from vulnerable households to professional staff. It also requires knowledge among staff of local culture, deprivation and need, and the cultural competence and sensitivity to undertake better outreach, prevention work and support for people to move out of crisis.

The second 'best practice' addresses the importance of providing the physical structure and infrastructure that allows individuals to maintain local connection to place sustainably over time. This involves a larger structural shift in the provision of housing, the nature of planning, and the opportunities for employment in the area. As such, they lay outside the remit of the Housing Act, as did the wider context of austerity. The particular challenges of building genuinely affordable housing in the rural context - lack of land, small plots, local opposition to development, prices driven up through holiday homes and an influx of people of retirement age - all demanded local knowledge and relationships, political will and increased subsidy. While no one interviewed argued that housing was the only solution and there was need for wider support for people as they moved from crisis into stability, it was widely felt that interventions were limited where appropriate housing did not exist to move people into. The lack of services in rural settings to sustain a staircase approach to addressing homelessness - where service users move through a series of supported steps into permanent accommodation - gives an additional imperative to provide greater support in rural areas for homeless people. Housing First is a good example of this. In providing a home together with wrap-around services, Housing First approaches can contribute to embedding an individual in a supportive network (Jones, 2017; Stefancic and Tsemberis, 2007).

\section{Note}

1 The maximum amount that would be payable for rent to those reliant on state benefits.

\section{References}

Ahmed, A., Wilding, M., Gibbons, A., Jones, K., Rogers, M. and Madoc-Jones, I. (2017) Post-Implementation Evaluation of the Homelessness Legislation (Part 2 of the Housing Act (Wales) 2014) Interim Report, Cardiff: Welsh Government.

Ahmed, A., Wilding, M., Gibbons, A., Jones, K., Rogers, M. and Madoc-Jones, I. (2018) Post-Implementation Evaluation of Part 2 of the Housing Act (Wales) 2014: Final Report (No. GSR report number 46/2018), Cardiff: Welsh Government.

Argent, N. and Rolly, F. (2006) 'Inhabiting the margins: a geography of rural homelessness in Australia', in P. Milbourne and P. Cloke (eds.), International Perspectives on Rural Homelessness, London: Routledge, 208-30.

Baker, K. J., Mould, R., Stewart, F., Restrick, S., Melone, H. and Atterson, B. (2019) 'Never try and face the journey alone: exploring the face-to-face advocacy needs of fuel poor householders in the United Kingdom', Energy Research and Social Science, 51, 210-19. 
Blythe, H. (2006) The Stigma of Rural Homelessness in Wales, Cardiff: Wallich Clifford Community.

Bramley, G. and Fitzpatrick, S. (2018) 'Homelessness in the UK: who is most at risk?' Housing Studies, 33, $1,1-21$.

Busch-Geertsema, V. and Fitzpatrick, S. (2008) 'Effective homelessness prevention? Explaining reductions in homelessness in Germany and England', European Journal of Homelessness, 2, 69-95.

Carpenter-Song, E., Ferron, J. and Kobylenski, S. (2016) 'Social exclusion and survival for families facing homelessness in rural New England', Journal of Social Distress and the Homeless, 25, $1,41-52$.

Chambers, P. and Thompson, A. (2005) 'Public religion and political change in Wales', Sociology, 39, 1, 29-46.

Cloke, P., Milbourne, P. and Widdowfield, R. (2001a) 'Interconnecting housing, homelessness and rurality: evidence from local authority homelessness officers in England and Wales', Journal of Rural Studies, 17, 99-111.

Cloke, P., Milbourne, P. and Widdowfield, R. (2001b) 'Homelessness and rurality: exploring connections in local spaces of rural England', Sociologia Ruralis, 41, 4, 438-53.

Commission on Rural Housing in Wales (2008) Final Report of the JRF Commission on Rural Housing in Wales, York: JRF.

Culhane, D. P., Metraux, S. and Byrne, T. (2011) 'A prevention-centered approach to homelessness assistance: a paradigm shift?', Housing Policy Debate, 21, 2, 295-315.

Day, G. and Jones, D. (2006) 'Civil society and the institutions of economic development', in G. Day, D. Dunkerley and A. Thompson (eds.), Civil Society in Wales: Politics, policy and people, Cardiff: University of Wales Press, 39-64.

First, R. J., Rife, J. C. and Toomey, B. G. (1994) 'Homelessness in rural areas: causes, patterns, and trends', Social Work, 39, 1, 97-108.

Fitzpatrick, S., Johnsen, S. and Watts, B. (2012) International Homelessness Policy Review: A Report to Inform the Review of Homelessness Legislation in Wales, Cardiff: Welsh Government.

Fitzpatrick, S., Pawson, H., Bramley, G., Wilcox, S. and Wood, J. (2017) The Homelessness Monitor: Wales 2017, https://www.crisis.org.uk/ending-homelessness/homelessness-knowledge-hub/homelessnessmonitor/wales/the-homelessness-monitor-wales-2017/ [accessed 22.08.2018].

Gallent, N., Mace, N. and Tewdwr-Jones, M. (2018) 'The impacts of second homes', in N. Gallent and M. Tewdwr-Jones (eds.), Rural Second Homes in Europe: Examining Housing Supply and Planning Control, London: Routledge, 55-86.

Gray, D., Shaw, J. and Farrington, J. (2006) 'Community transport, social capital and social exclusion in rural areas', Area, 38, 1, 89-98.

Inkson, S. (2009) The Effects of Recent Migration on Local Authorities' Allocation of Housing and Actions under Homelessness Legislation: A Study in Six Local Authorities, Cardiff: Welsh Government.

Institute for Welsh Affairs (2006) Future of Social Housing in Wales, Cardiff.

Jones, A. (2017) 'Housing First Project' Isle of Anglesey County Council, https://chcymru.org.uk/uploads/ events_attachments/What_is_Housing_First.pdf [accessed 13.06.2019].

Kitchen, L. and Milbourne, P. (2006) Housing Need in rural Wales: Towards Sustainable Solutions, WRO Research Report No. 10, Cardiff: Wales Rural Observatory.

Lawrence, M. (1995) 'Rural homelessness: a geography without a geography', Journal of Rural Studies, 11, 3, 297-307.

Mackie, P. (2014) 'The Welsh homelessness legislation review: delivering universal access to appropriate assistance', Contemporary Wales, 27, 1-20.

Mackie, P., Fitzpatrick, S., Stirling, T., Johnsen, S. and Hoffman, S. (2012) Options for an Improved Homelessness Legislative Framework In Wales: A Report to Inform the Review of Homelessness Legislation in Wales, Cardiff: Welsh Government.

Madoc-Jones, I., Parry, O. and Hughes, C. (2012) 'Minority language non-use in service settings: what we know, how we know it and what we might not know', Current Issues in Language Planning, 13, 3, 249-62. 
Mann, R. (2006) 'Between consent and coercion: civil society, bilingualism and the Welsh language', in G. Day, D. Dunkerley and A. Thompson (eds.), Civil Society in Wales: Politics, Policy and People, Cardiff: University of Wales Press, 252-68.

Melucci, A. (1994) 'A strange kind of newness: what's new in new social movements?', in E. Larana, H. Johnson and J. Gusfield (eds.), New Social Movements: From Ideology to Identity, Philadelphia: Temple University Press, 101-30.

Milbourne, P. (2012) 'Poverty in rural wales: material hardship and social inclusion', in P. Milbourne (ed.), Rural Wales in the Twenty-First Century: Society, Economy and Environment, Cardiff: University of Wales Press, 254-70.

Milbourne, P. and Cloke, P. (eds.) (2006) International Perspectives on Rural Homelessness, London and New York: Routledge.

Milbourne, P., Hughes, R. and Hartwell, S. (2006) Homelessness in Rural Wales, WRO Research Report No. 9, Cardiff: Wales Rural Observatory.

Office for National Statistics (ONS) (2018) 2011 Census Analysis - Comparing Rural and Urban Areas of England and Wales, https://www.basw.co.uk/system/files/resources/basw_41648-6_0.pdf [accessed 24.03.2019].

Pritchard, A. and Morgan, N. (2003) 'Mythic geographies of representation and identity: contemporary postcards of Wales', Tourism and Cultural Change, 1, 2, 111-30.

Public Policy Institute for Wales (2016) Rural Poverty in Wales: Existing Research and Evidence Gaps, Cardiff: Public Policy Institute for Wales, http://ppiw.org.uk/files/2016/06/An-introduction-to-RuralPoverty.pdf [accessed 24.03.2019].

Robinson, D. (2004) 'Rough sleeping in rural England: challenging a problem denied', Policy and Politics, $32,4,471-86$.

Robinson, D. and Coward, S. (2003) Hidden Homelessness: Your Place, Not Mine: The Experiences of Homeless People Staying With Family and Friends, London: Crisis and the Countryside Agency.

Rogers, A. (1985) 'Local claims on rural housing: a review', Town Planning Review, 56, 3, 367-80.

Rural Housing Solutions, Cyngor Da, Three Dragons (2014) An Evaluation of the Rural Housing Enablers in Wales: Literature Review (No. 7/2014), Merthyr Tydfil: Welsh Government.

Sandberg, L. (2013) 'Backward, dumb, and violent hillbillies? Rural geographies and intersectional studies on intimate partner violence', Affilia, 28, 4, 350-65.

Shapiro, S. (2014) Homelessness in Rural America, National Advisory Committee on Rural Health and Human Services.

Snelling, C. (2017) Right to Home? Rethinking Homelessness in Rural Communities, Institute for Public Policy Research.

Stefancic, A. and Tsemberis, S. (2007) 'Housing First for long-term shelter dwellers with psychiatric disabilities in a suburban county: a four-year study of housing access and retention', Journal of Primary Prevention, 28, 265-79.

Stephenson, J. (ed.) (2001) Teaching and Learning Online: Pedagogies for New Technologies, London: Kogan Page.

Waegemakers Schiff, J., Schiff, R., Turner, A. and Bernard, K. (2015) 'Rural homelessness in Canada: directions for planning and research', Journal of Rural Community Development, 10, 4, 85-106.

Welsh Government (2008) A Statistical Focus on Rural Wales, 2008 Edition, http://gov.wales/docs/statistics/ 2008/080515-statistical-focus-rural-wales-08-en.pdf [accessed 15.08.2018].

Welsh Government (2016) Code of Guidance for Local Authorities on the Allocation of Accommodation and Homelessness, Cardiff: Welsh Government.

Welsh Government (2018a) Rural Housing, https://gov.wales/topics/housing-and-regeneration/housingsupply/rural/?lang=en [accessed 02.12.19].

Welsh Government (2018b) Wales Statistics on Homelessness, https:/gov.wales/statistics-and-research/ national-rough-sleeping-count/?tab=previous\&lang=en [accessed 22.08.2018].

Williams, E. and Doyle, R. (2016) 'Rural Poverty in Wales: Existing Research and Evidence Gaps', Public Policy Institute for Wales. 